\title{
Nanocomposites for Engineering Applications
}

\author{
Alan K. T. Lau, ${ }^{1}$ Debes Bhattacharyya, ${ }^{2}$ and Carrie H. Y. Ling ${ }^{3}$ \\ ${ }^{1}$ Department of Mechanical Engineering, The Hong Kong Polytechnic University, Hong Kong \\ ${ }^{2}$ Department of Mechanical Engineering, Centre for Advanced Composite Materials, The University of Auckland, \\ Auckland 1142, New Zealand \\ ${ }^{3}$ Department of Mechanical Engineering, Stanford University, Stanford, CA 94305, USA
}

Correspondence should be addressed to Alan K. T. Lau, mmktlau@polyu.edu.hk

Received 16 July 2009; Accepted 16 July 2009

Copyright ( 2009 Alan K. T. Lau et al. This is an open access article distributed under the Creative Commons Attribution License, which permits unrestricted use, distribution, and reproduction in any medium, provided the original work is properly cited.

Advanced polymer-based nanocomposite materials have gained popularity for wide engineering applications with improving virtually all types of products and commercialization of products that exploit their unique mechanical, thermal, and electrical properties. However, these properties present new challenges to understand, predict, and manage potential adverse effects, such as toxicity impacts exposure to human lives and environment. Thus, widespread applications of nanomaterials induce enormous potentials positively and negatively for human exposure and environmental release. Federal budget also emphasizes these implications and it is expected that the total annual budget for various sectors from the National Nanotechnology Initiatives will increase substantially in the coming years.

The applications of nanostructure resins for biological applications have been conducted in vitro and in vivo environments in research in the past few years. The evaluation involved how the resins can bond for biocompatibility to bone for repair after breaking, teeth for filling, other various types of tissues for wound healing, and so on. Natural and synthetic polymeric materials have been found to be suitable for tissue engineering applications. For an example, silk (like cocoon or spider) fiber /biodegradable polymer biocomposites have been used for tissue engineering (scaffolding) for bone repair. Many researches have also demonstrated the use of nano structural materials as reinforcements, such as nano apatite, nanoclay, and nanofibers (polymer-based or carbon nanotubes) to enhance the mechanical properties and thermal stability of bio compatible polymers for artificial joints and scaffolding. Tissue engineering is one such aspect that utilizes both engineering and life science disciplines to either maintain existing tissue structures or to enable tissue growth. Furthermore, tissue-engineered organs can be used in testing procedures, reducing or eliminating the need for animal subjects. Nano biotechnology is an interdisciplinary field resulting from the interfaces between biotechnology, materials science, and nanotechnology.

This special issue "Nanocomposites for Engineering Applications" covers a wide range of papers contributed by authors around the world on the nanocomposites and their structural and mechanical properties. This aim is to provide a platform for scientists and researchers to exchange and share ideas and findings in the field.

Alan K. T. Lau Debes Bhattacharyya Carrie H. Y. Ling

\section{Acknowledgments}

The editors would like to express their sincere appreciation and thanks to all the authors and co authors for their scientific contribution to this special issue. We convey our gratitude to all the reviewers for their time and dedication. 

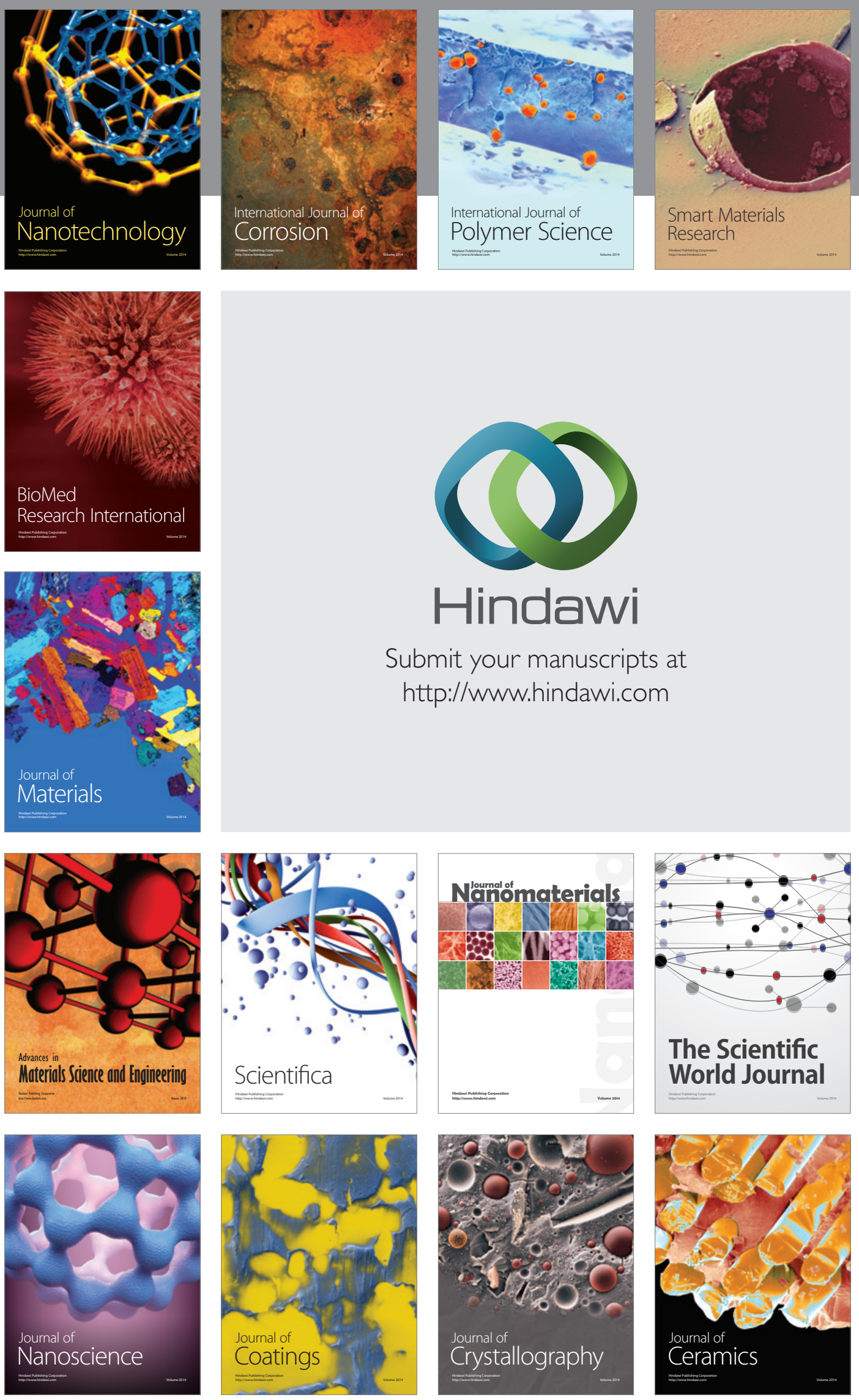

The Scientific World Journal

Submit your manuscripts at

http://www.hindawi.com

\section{World Journal}

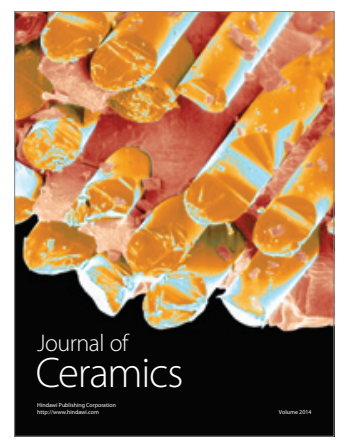

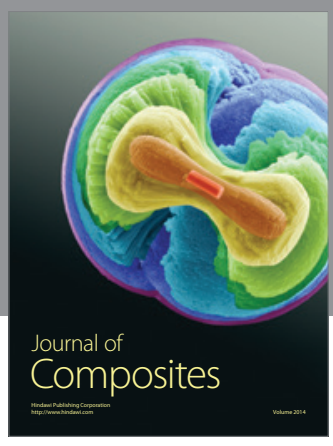
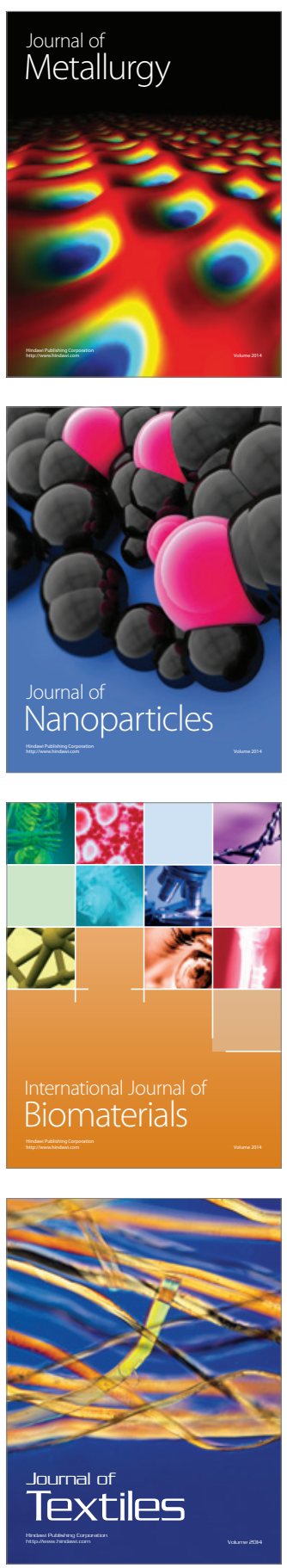